\title{
Prensa y poder en los inicios de la democracia. Los orígenes de la infoxicación en la comunicación institucional. El caso de Huelva
}

institucional.us.es/ambitos/

Mari Paz Díaz Domínguez

Universidad de Huelva

maripaz.diaz@dhis2.uhu.es

Resumen

La infoxicación es un fenómeno donde las instituciones públicas han tenido un papel relevante. La interrelación comenzó con la democracia al ser entonces cuando las administraciones sienten la necesidad de comunicarse con la sociedad. Surgen los gabinetes de prensa, una de las principales fuentes de los medios. En este contexto, fijamos nuestra mirada en Huelva, haciendo un recorrido por la prensa onubense para conocer cuáles han sido las primeras publicaciones periódicas generadas por las administraciones, al hilo de los nuevos aires de libertad que vivía el país tras décadas de dictadura. Así se sentaron las bases del panorama actual.

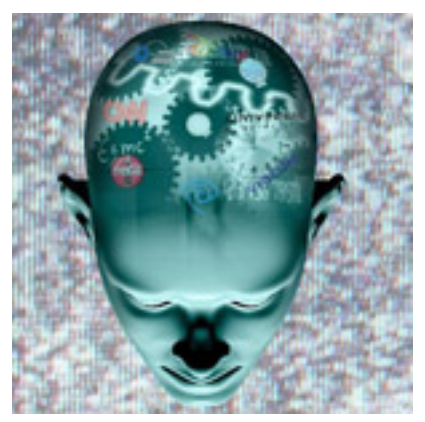

\section{Palabras clave}

Prensa, comunicación, institucional, democracia, Huelva.

\begin{abstract}
Information overload is a phenomenon where public institutions have an important role. The interrelation between the two began with democracy being so when the authorities feel the need to communicate with society. Arise press, one of the main sources of media cabinets. In this context, we fix our gaze in Huelva, making a tour of the Huelva press to know what had been the first periodical publications generated by the administrations, in line with the new air of freedom living the country after decades of dictatorship. So we sat down the foundations of the current scene.
\end{abstract}

\section{Keywords}

Press, communication, institutions, democracy, Huelva.

\section{INTRODUCCIÓN}

La instauración del sistema democrático en España tras la dictadura obligó al país a una redefinición de las instituciones públicas. Y no sólo de los ayuntamientos y diputaciones, sino también de los nuevos órganos surgidos dentro del mapa autonómico, como sucedió con la Junta de Andalucía.

En este contexto, el periodismo inició una nueva relación con las administraciones. De un lado, los gestores públicos encontraron en la prensa una vía para transmitir a los ciudadanos sus actuaciones, mientras que la publicidad institucional y política se convierte en una de las principales fuentes de información de los mass media. A reglón seguido se produjo la proliferación de los gabinetes de prensa, entidades que generaron sus propias publicaciones, cuyo "único interés radica en servir de orientación y guía a los vecinos" (Cal: 1989, 493). $Y$ es que entonces todo era nuevo.

Huelva se suma a este proceso con la difusión de boletines creados desde las instituciones públicas, especialmente en los años ochenta, unos títulos de carácter gratuito que se caracterizaron por su calidad. La mayoría de ellos ha desaparecido. Y, aunque en la actualidad este tipo de cabeceras se ha visto suplido por el envío de notas de prensa y convocatorias dirigidas a los medios de comunicación, las instituciones onubenses 
han venido realizando sus propias aportaciones comunicativas desde el año 1976.

Fue el inicio de un proceso que ha derivado en un exceso de información procedente del poder establecido, hasta el punto de que hoy en día son las instituciones las que marcan la agenda del periodista y, por tanto, las noticias seleccionadas para divulgar en cada medio.

Un proceso paulatino que ha dado lugar a una sobrecarga informativa, es decir, infoxicación. Porque del exceso de información que llega a diario a los ciudadanos también son culpables las administraciones públicas. Tanto que, a veces, el receptor no tiene la capacidad de diferenciar o digerir los mensajes que son emitidos a lo largo del día. Incluido cuando son generados desde las instituciones.

El término de infoxicación (del inglés information overload) fue acuñado por primera vez en 1970 por Alvin Toffler en su libro Future Shock. Y, precisamente, fue en la década de los setenta cuando en España se sientan las bases de la información institucional actual. Huelva es un buen ejemplo de ello, por lo que su caso podría extrapolarse al resto de provincias españolas, así como a un ámbito regional o nacional.

Este concepto fue introducido en España por investigadores como Alfons Cornella (Cornella: 1996, 1), si bien, en los últimos años, científicos de diversas disciplinas -incluido del ámbito de la Salud- se han mostrado preocupados por las consecuencias de la infoxicación y cómo combatirla, especialmente tras la proliferación del uso de internet, que ha agudizado el problema (Navas-Martin: 2012, 2).

Con todo, nos trasladamos hasta la Huelva de inicios de la democracia española para comprender el contexto inicial que ha creado el exceso de información institucional actual, tal y como queda patente en los medios de comunicación, no sólo de la provincia onubense, sino de forma general.

\section{EL INICIO DE LA DEMOCRACIA EN ESPAÑA: LAS INSTITUCIONES Y LOS MEDIOS DE COMUNICACIÓN SE DAN LA MANO}

Con la muerte de Franco, el 20 de noviembre de 1975 se inicia la Transición Democrática, un proceso cuyo punto culmen fue la aprobación de la Constitución española de 1978, donde se recogían "las libertades de reunión, asociación y expresión" (Escobar: 2002, 192-193). Además, el artículo 20 del texto constitucional declaraba la libertad de expresión (Rausell: 2002, 132), tan sólo limitada por el derecho al honor, a la intimidad, a la propia imagen y a la juventud y la infancia.

Todo ello permitió que la prensa jugara un papel protagonista en la transición (Farias: 1999, 73), configurándose como una herramienta insustituible en el debate democrático (Muñoz: 2007, 461). Era el fin de una etapa en la que, poco a poco, se consolidaban propuestas periodísticas novedosas, como El País.

La transición fue, por tanto, un momento de renovación total. Una filosofía que se instala también en la prensa de provincias, donde surgen nuevos periódicos, especialmente a partir de 1975-1980 (Ruiz: 1998, 240). En el caso onubense, este proceso fue un poco más tardío, al producirse en la década de los ochenta.

La renovación mediática no sólo afectó a la prensa diaria, puesto que el interés por la comunicación se instaló en todos los sectores de la población, lo que se tradujo en un desarrollo sin precedentes del periodismo especializado. Era lógico. Después de las restricciones de la dictadura, los colectivos y entidades (sindicatos, organizaciones empresariales, profesionales, administraciones, vecinos...) tenían ansías por expresarse, de ejercer el derecho a la libertad de expresión.

En la proliferación de estas publicaciones fue determinante la consolidación de las nuevas instituciones públicas: ayuntamientos, diputaciones y comunidades autónomas. Todas ellas sentirán la necesidad de dar a conocer su gestión entre los ciudadanos a través de la prensa (Checa: 1991, 469).

De forma paralela, en la etapa predemocrática se registró un tremendo auge de lo local, un interés creciente por lo más cercano, ya fuera el pueblo o comunidad de vecinos. Así sucedió en Huelva, donde surgieron nuevas asociaciones por doquier (Feria: 2009,62). La sociedad onubense era más compleja y, por tanto, más propicia para contar con una prensa especializada rica. 
Siendo así, a continuación mostramos cuáles fueron esas nuevas publicaciones surgidas en Huelva durante la transición y los inicios de la democracia en el seno de las administraciones públicas. Un análisis en el que hemos clasificado las cabeceras según las entidades que las impulsaron para facilitar la comprensión del lector:

\subsection{La prensa municipal surgida del Ayuntamiento de Huelva}

Nada más iniciarse la Transición Democrática, el Ayuntamiento de Huelva pone en marcha su propio boletín informativo, una auténtica novedad puesto que la ciudad no veía una gaceta de estas características prácticamente desde la Segunda República. Se llamó Boletín Informativo Municipal de Huelva y tuvo la autorización necesaria para publicarse el 30 de septiembre de 1976.

Hay que recordar que el verdadero cambio en la vida municipal en España se produjo con las primeras elecciones municipales del 3 de abril de 1979, celebradas tras tres años de interinidad (Grijelmo: 1996, 371). Hacía cuatro décadas que los alcaldes no se elegían de forma democrática.

La revista nacía con el objetivo de informar al ciudadano de la vida municipal: los debates plenarios, acuerdos políticos y otros asuntos dentro de las competencias municipales (urbanismo, servicios sociales, cultura, deporte...). El resto de sus páginas se completaba con una agenda, información de cómo realizar gestiones municipales o entrevistas al alcalde y demás miembros del equipo de gobierno local.

El Boletín Municipal era trimestral. Su formato era de tamaño folio y se imprimía en offset. Se editaba desde la Imprenta de Guillermo Martín, situada en la Plaza José Antonio de Huelva. Contaba con unos 300 ejemplares de tirada. Por su carácter público, no aceptaba publicidad y su distribución era gratuita. Su director fue el alcalde de la ciudad de Huelva, Carmelo Romero Núñez, mientras que la redacción la realizaban los trabajadores de la plantilla del Ayuntamiento de Huelva.

Pero más allá de sus características, la importancia de este tipo de boletines radica en el mismo hecho de su publicación, pues nos aporta una visión muy clara del papel que jugaron los ayuntamientos en la etapa predemocrática, rompiendo el control al que se vieron sometidos en la dictadura. Hay que tener en cuenta que tan sólo un día antes del fallecimiento de Franco se aprobaba la Ley de Bases de Régimen Local, que mantenía intactas la dependencia de los consistorios del ministro de la Gobernación y del director general de la Administración Local (Nicolás: 2007, 260).

La intensa vida municipal se tradujo en la aparición de más de una publicación municipal en Huelva, como sucede con Lluvia (1982), un magazine que se enmarcaba dentro del plan de dinamización cultural del ayuntamiento (Checa: 1991, 470). La propuesta era muy similar a otros proyectos periodísticos que se han lanzado desde el Ayuntamiento de Huelva en los últimos años. Un buen ejemplo de esta afirmación lo encontramos en la revista Ipunto (2006), una cabecera del Centro Juvenil de Huelva, dependiente de la Concejalía de Familia, Servicios Sociales y Juventud del Consistorio capitalino (Fotografía 1). 


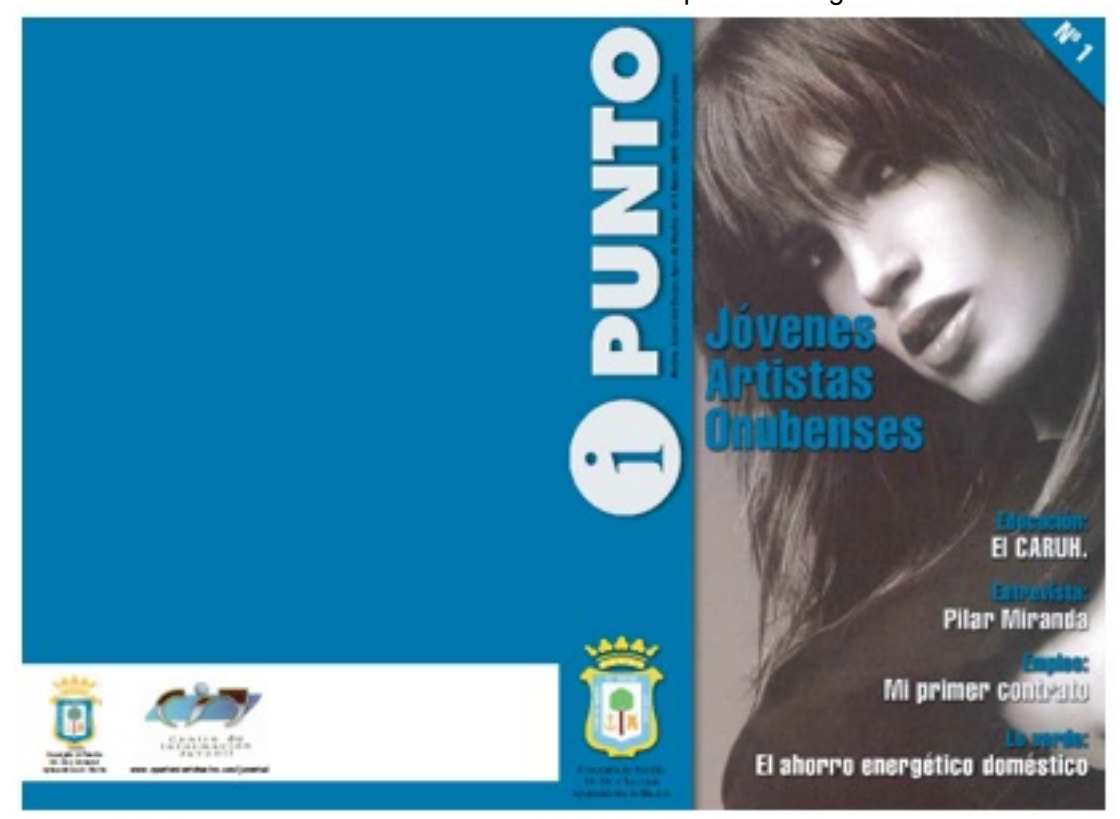

Boletín Ipunto del Ayuntamiento de Huelva (2006).

Fuente: Ayuntamiento de Huelva (www.huelva.es).

Se trata de una gaceta dirigida a mostrar las actividades que se organizan en la ciudad para el colectivo juvenil. Empleo, ecología, vivienda, universidad..., son sólo algunos de los temas tratados en las páginas de este boletín de distribución gratuita. El impreso, coordinado por Antonio Bello, nacía con diseño de GAM Artes Gráficas, aunque en números posteriores este cometido pasó a la empresa de comunicación IGS. Su puesta en marcha se llevó a cabo siendo Pilar Miranda concejala de Juventud. El primer número de Ipunto apareció en marzo de 2006.

Pero volviendo a comienzos de los años ochenta, debemos tener en cuenta que Lluvia fue una revista novedosa que plasmaba la preocupación de los primeros gobiernos locales democráticos por la cultura y el ocio.

Es más, uno año más tarde aparecería una nueva cabecera del Ayuntamiento: Huelva Municipal, 'Revista Informativa del Ayuntamiento' (1983 - 1995), una publicación que nace a inicios de los años ochenta (Braojos: 1985), siendo alcalde de la ciudad José Antonio Marín Rite. Esta gaceta representaba la consolidación de la democracia en el Consistorio capitalino, puesto que su edición logró mantenerse durante dos legislaturas. Es decir, el sucesor de Marín Rite, el también socialista Juan Ceada, mantuvo la cabecera (Fotografía 2). 
Todo parece indicar que la revista cesó en 1995, coincidiendo con la llegada a la Alcaldía de Huelva del popular Pedro Rodríguez (VV.AA: 2007). La periodicidad de la cabecera fue irregular, pues en septiembre de 1984 publicó su número 3, mientras que en 1992 editó el 13.

Huelva Municipal inició su andadura bajo la dirección de Ángela Blanco Niquele, presidenta de la Asociación de la Prensa de Huelva en 1988. Tras Ángela Blanco, en los años noventa, sería María Ángeles Puente la encargada de su elaboración como responsable del gabinete de prensa del Ayuntamiento de Huelva. Es decir, el boletín estaba confeccionado por periodistas profesionales frente a la gaceta municipal anterior, que la redactaban los funcionarios del ayuntamiento.

En cuanto a su contenido, Huelva Municipal recogía toda la información que generaba el Consistorio, así como los acontecimientos más relevantes que sucedían en la ciudad, ya fuera el Festival Iberoamericano de la Canción en La

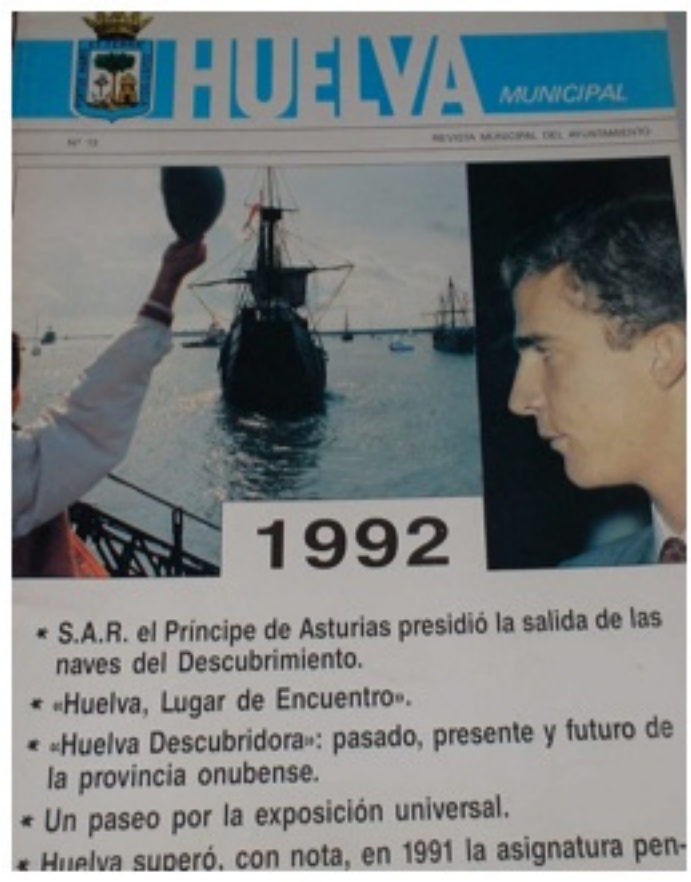

Revista Huelva Municipal (1983 - 1995).

Fuente: Archivo privado de José Luis Jerez Manfredi. Rábida, las corridas de toros en Colombinas, el primer vuelo en globo España-América desde Huelva o el Carnaval Colombino. Es importante reseñar que en sus páginas no sólo aparecían las actuaciones del equipo de gobierno, sino también las cuestiones de los grupos de la oposición, algo inusual en la actualidad. La gaceta solía comenzar con una editorial firmada por el alcalde de la ciudad, tras la que se distribuían secciones como 'Cultura', 'Deportes', 'Bienestar Social', 'Medio Ambiente' o 'Hacienda'. Por último, en 'Recortes' se mostraban imágenes a modo de fotonoticias con los hechos de mayor interés que habían ocurrido a lo largo del último año en Huelva.

Un número mítico de Huelva Municipal fue el que publicó en el año 1992, conmemorativo del V Centenario del Descubrimiento de América. Entonces, la dirección de la revista corría a cargo de la misma María Ángeles Puente, mientras que Juan Vázquez Pavón era el delegado de información, siendo alcalde Juan Ceada.

En cuanto a su formato, en los años noventa, la revista se editaba en A-4 desde la Imprenta Jiménez. Su maquetación era de corte clásico y equilibrado, propia de un magazine oficial. En Huelva Municipal se prefería utilizar poco texto, con titulares, entradillas y ladillos en negrita y muchas imágenes a color. Su financiación corría a cargo del Ayuntamiento, puesto que no tenía publicidad.

\subsection{La información generada por la Diputación de Huelva}

Además del Ayuntamiento de Huelva, otras administraciones públicas sacaron sus propias publicaciones periódicas en esta etapa, como sucede desde 1980 con la Diputación Provincial, que editó la revista Huelva $(1980-1984)$.

Huelva fue la primera revista de la Diputación Provincial de Huelva -si exceptuamos el Boletín Oficial de la Provincia. Esta publicación nació en 1980 y se mantuvo hasta 1984. Su distribución era gratuita y, aunque en un principio tuvo una tirada de 1.500 ejemplares, poco después se amplió a los 2.000 . El boletín, además, se enviaba por correo a los onubenses que se encontraban fueran de Huelva. Su periodicidad fue trimensual, a pesar de que intentó sin éxito convertirse en bimensual (Fotografía 3). 
Dirigida por Pedro Jurado Hachero, presidente de la Comisión de Cultura de la Diputación Provincial, Huelva se realizaba desde el gabinete de prensa de la institución provincial. Entonces, esta tarea era responsabilidad del periodista Rafael J. Terán, que recuerda que fueron años intensos para el periodismo, ya que para las instituciones públicas todo era nuevo, "había que ir reinventando el sistema democrático tras años de dictadura", asegura (Fotografía 4). En este momento, el Gobierno de la Diputación estaba en manos de la UCD. La presidencia de la institución estuvo ocupada en la transición por Felipe Martínez de Acuña, al que sustituyó en un breve mandato Jaime Madruga y, después, Emiliano Sanz Escalera.

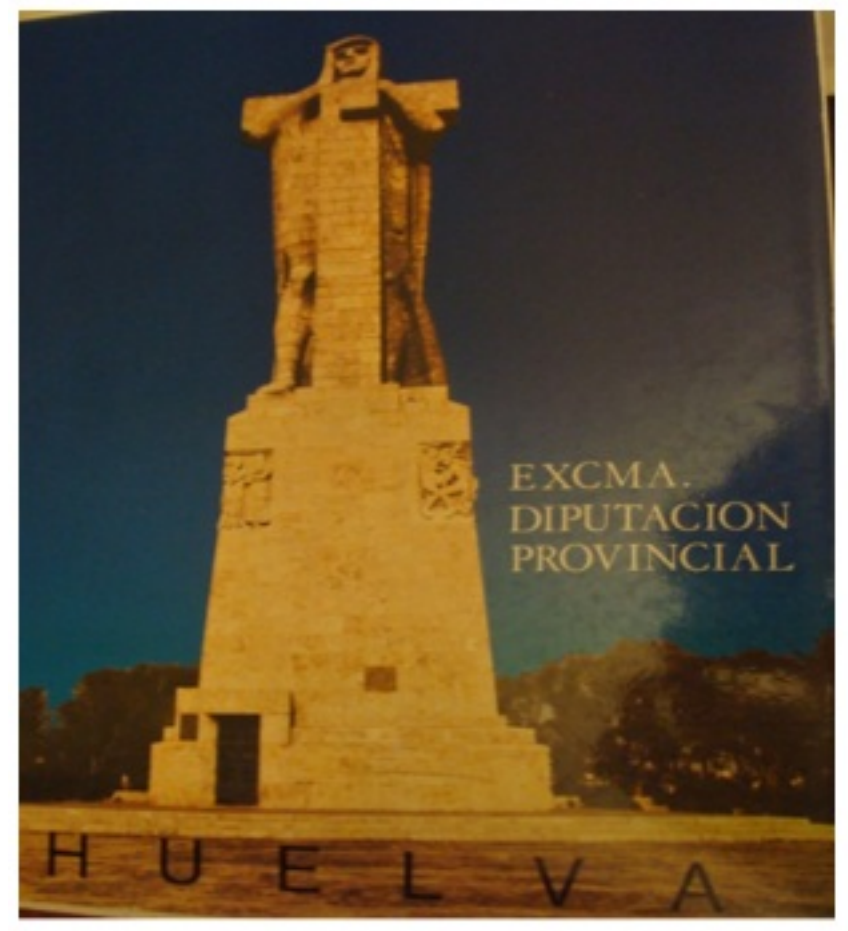

Huelva (1980), editada por la Diputación Provincial de Huelva. Fuente: Archivo privado de Rafael Terán.

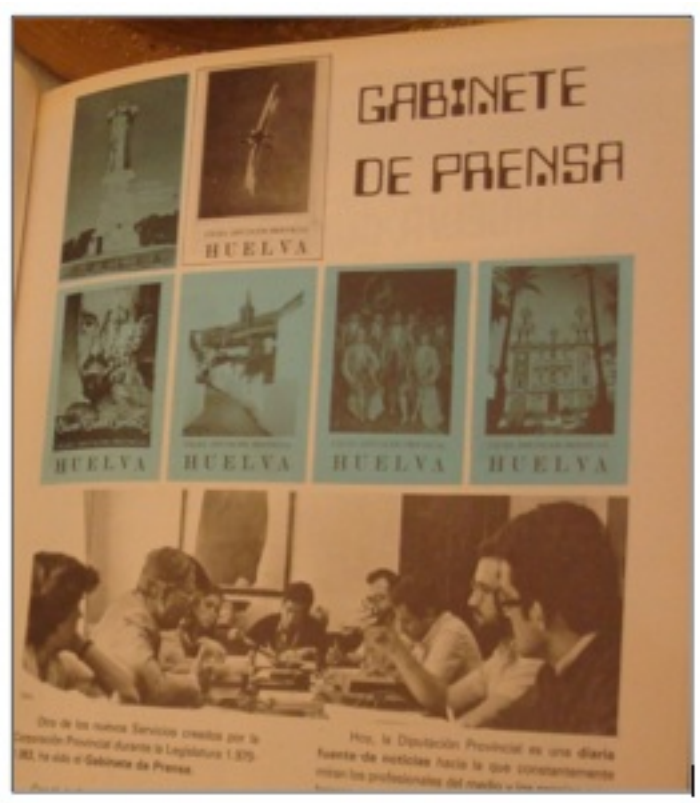

Huelva (1980), editada por la Diputación Provincial de Huelva. Fuente: Archivo privado de Rafael Terán.

El objetivo de Huelva era mostrar a la población las gestiones que llevaba a cabo la Diputación Provincial, incluidos los grupos de la oposición, con reportajes amplios en los que se presentaba a cada uno de los diputados onubenses de esos años a modo de balance. Por ello, Huelva es un documento de enorme interés para conocer cómo funcionaba la Diputación a inicios de los ochenta, así como para acercarse a los grandes proyectos que se ponían en marcha, como sucedió con la construcción del nuevo hospital provincial, el 'Infanta Elena' (Fotografía 5). Otros autores, como Checa Godoy, resaltan sus contenidos históricos y culturales (Checa: 2011, 521). 


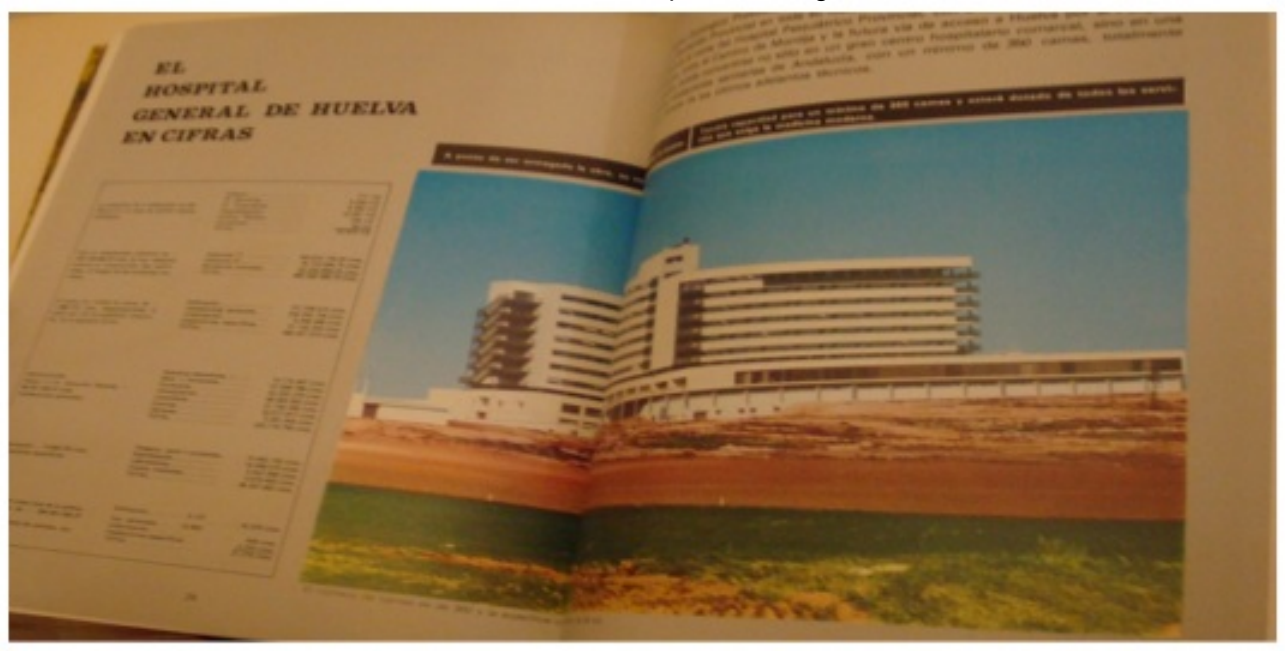

Huelva (1980), editada por la Diputación Provincial de Huelva.

Fuente: Archivo privado de Rafael Terán.

En general, este trimensual presentó una estructura organizada y clara, que podía seguirse en su sumario. La maqueta de la revista la realizaba Víctor Faure. Se editaba a color en formato A-4. Tenía entre 60 y 80 páginas de calidad, donde se cuidaban los espacios en blanco, con planillos a dos o tres columnas, priorizando las fotografías. Otro recurso habitual fue la introducción de tramas a color para los suplementos, una técnica que le otorgaba un carácter especial a ese artículo, tal y como ocurre con ocasión de un balance de la gestión llevada a cabo por la Diputación entre 1980 y 1983. Estas páginas centrales se presentaron en color azul. Incluso, a veces, Huelva incluyó desplegables a todo color de enorme calidad.

Tras la desaparición de esta revista, la Diputación Provincial continuó publicando su propio boletín informativo, aunque con un nombre diferente. Se trató de Huelva 79, bajo la dirección de Inmaculada González.

Huelva 79 fue la evolución de la revista anterior. La nueva publicación iniciaba su andadura hacia 1986, año en el que Inmaculada González ocupa la jefatura del gabinete de prensa de la Diputación Provincial y pasa a dirigir la revista. González permaneció al frente del gabinete durante nueve años, por lo que es probable que esta cabecera se mantuviera durante este mismo periodo de tiempo.

La revista era de carácter trimestral y su objetivo fue dar a conocer la gestión de la Diputación Provincial de Huelva. De hecho, el cambio de denominación de la publicación no era casual, porque el '79' se refería al número de municipios que conforman la provincia. De este modo, "se pretendía acercar la Diputación a toda la geografía provincial, al mismo tiempo que se fomentaba la integración de cada una de las localidades", según recuerda la propia Inmaculada González. Por este motivo, en la gaceta se ofrecieron amplios reportajes de cada uno de los municipios onubenses, una tarea que realizó Margarita Vázquez, que hoy continúa trabajando en el gabinete de prensa del organismo supramunicipal.

Otro cambio en la nueva etapa de la revista fue la introducción en su portada de una obra pictórica realizada por algún artista onubense, como fue el caso de José Carlos Castro Crespo, Overli y José Oliva, entre otros.

En definitiva, Huelva 79 fue una apuesta de calidad, que se presentaba con un formato cuidado y donde primaba la necesidad de conectar la institución provincial con el resto de la sociedad onubense.

Junto a las dos publicaciones anteriores debemos recordar que la Diputación continúa difundiendo el Boletín Oficial de la Provincia de Huelva (BOP), nacido en 1834, un "periódico oficial en el que se publican las disposiciones de carácter general y las ordenanzas, los actos, edictos, acuerdos, notificaciones, anuncios y demás resoluciones de las Administraciones Públicas y de la Administración de Justicia del ámbito territorial de la provincia de Huelva".

Su edición se llevaba a cabo en la Imprenta Provincial, pero en la actualidad se puede consultar en formato digital en la página web de la Diputación (www.diphuelva.es). Sea en papel o en digital, la estructura del Boletín Oficial de la Provincia de Huelva ha variado poco a lo largo de su extensa trayectoria y, en general, cuenta con cinco secciones: Administración Local, Autonómica, del Estado, de Justicia y Anuncios en General y 
Con todo, la Diputación de Huelva publicó otras revistas en los años ochenta, aunque no directamente, sino a través del Patronato Provincial de Turismo, que en 1985 creó el magazine Huelva Costa de la Luz. La cabecera medía $22 \times 30$ centímetros y su finalidad fue mostrar las excelencias turísticas de la provincia de Huelva a través de amplios reportajes en los que primaban las fotografías. Entre los temas más recurrentes de la publicación se encontraron las playas de Huelva.

Mucho más recientemente, los funcionarios de la institución provincial han puesto en marcha una revista propia bajo el título de El Nexo que hace falta. Se trata de un semestral de la Asociación Cultural de Funcionarios y Empleados de la Diputación Provincial de Huelva (ACEF) para mejorar las relaciones entre los empleados de la administración. Editada por la Diputación Provincial, la cabecera inició su andadura en el año 1999, realizándose e imprimiéndose por la misma institución.

El director de Nexo fue Julián Álvarez Fernández, que estuvo acompañado por un consejo de redacción formado por Félix Sancha, José Luis Gozálvez, Pilar Muñoz, Lauro Anaya, Aquilino Pérez, Serafín García y Carlos Delgado. Cada uno de ellos se encargaba de gestionar una de las secciones del boletín: 'Los Pueblos', 'Corporación', 'Servicios de Personal', 'Cultura', 'Recuerdos', 'Entrevista. Humor. Música' y ‘Deportes', respectivamente. Además, Juan Fornalino, presidente de ACEF, María Luisa Omist y Félix Sancha eran miembros del Consejo de Administración del mensual. Sus páginas estaban abiertas a las colaboraciones de los trabajadores de la Diputación, como sucedía con las simpáticas viñetas que firmaba SerafínxDios.

Lo cierto es que esta revista fue un proyecto cuidado y equilibrado que ofrecía mucha información de interés tanto para los funcionarios, como para la ciudadanía onubense en general, ya que aparecían noticias de la Diputación, reportajes históricos, un recuerdo sobre las fiestas de Santa Rita, patrona de los funcionarios, monográficos sobre los pueblos de la provincia, entrevistas en profundidad. Los protagonistas de los textos y las fotografías insertadas solían ser los mismos trabajadores de la Diputación. Todo ello provocó que Nexo tuviera una enorme repercusión.

\subsection{La información regional generada por la Junta de Andalucía}

La configuración de la autonomía andaluza dio lugar a la creación de la Junta de Andalucía como su principal órgano de gobierno. Esta administración cuenta, a su vez, con delegaciones en las provincias de la comunidad, incluida Huelva. Su nacimiento en la Transición Democrática hizo que la Junta de Andalucía sintiera la necesidad de tener un medio de comunicación propio que le conectara con la sociedad.

Es así como surge la idea de lanzar la revista Huelva Junta, cuyo primer número apareció en enero de 1989. Por tanto, el boletín vio la luz un poco más tarde que las publicaciones institucionales del Ayuntamiento de Huelva o la Diputación. Era lógico si tenemos en cuenta que la Junta de Andalucía no se había creado como órgano de gobierno preautonómico hasta el 28 de abril de 1978, contando con Plácido Fernández Viagas como presidente (Ruiz: 2001, 1). Es decir, su recorrido era menor al resto de administraciones públicas (Fotografía 6). 


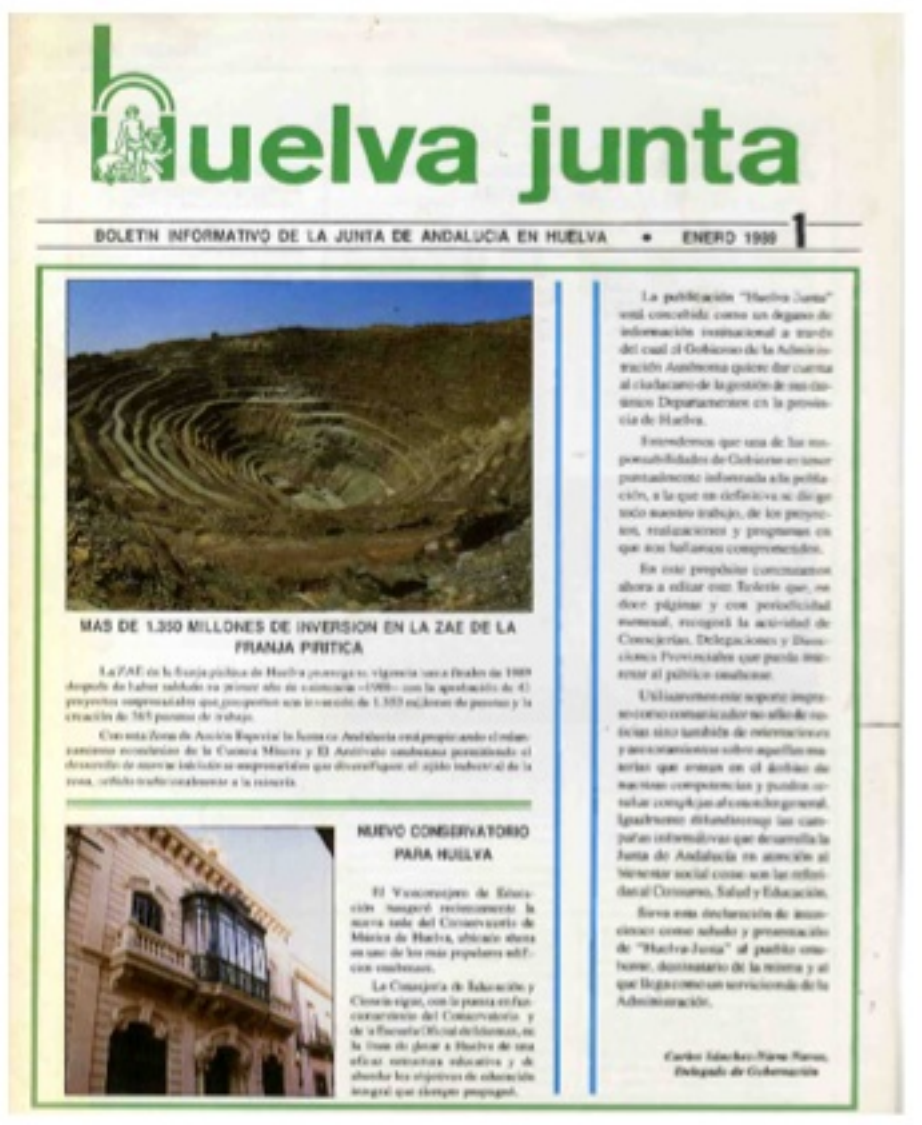

Huelva Junta (1980), editada por la Junta de Andalucla en Huelva.

Fuente: Archivo privado de Gloria Menéndez.

En este contexto apareció Huelva Junta, 'Boletín Informativo de la Junta de Andalucía en Huelva', que se elaboraba en el gabinete de prensa de la Delegación del Gobierno andaluz en la provincia, entonces dirigido por Gloria Menéndez. El periódico era mensual y se presentaba con 12 páginas. Su finalidad era dar cuenta a los ciudadanos de la gestión de la Administración autonómica, "porque entendemos que una de las responsabilidades de Gobierno es tener puntualmente informada a la población, a la que en definitiva se dirige todo nuestro trabajo", según explicaba en la editorial de presentación el delegado de Gobierno andaluz en Huelva, Carlos Sánchez-Nieva Navas, que estuvo en el cargo entre 1988 y 1994. Es decir, de nuevo, era una apuesta a favor de la transparencia en la gestión pública frente a la etapa anterior.

Siendo así, la lectura de la revista nos permite conocer los temas de mayor preocupación de los onubenses al filo de los noventa. Fue el caso de la necesidad de reactivar la actividad minera en Huelva, la puesta en marcha de una tercera facultad como requisito para la creación de la Universidad o la generación de nuevos regadíos para la agricultura, situándose ya en primer plano el cultivo de la fresa. Interesante fue también la atención que le prestó el boletín a la cuestión medioambiental de Huelva, el sector industrial onubense y los preparativos del $\checkmark$ Centenario del Descubrimiento de América en materia de infraestructuras (Fotografía 7). 


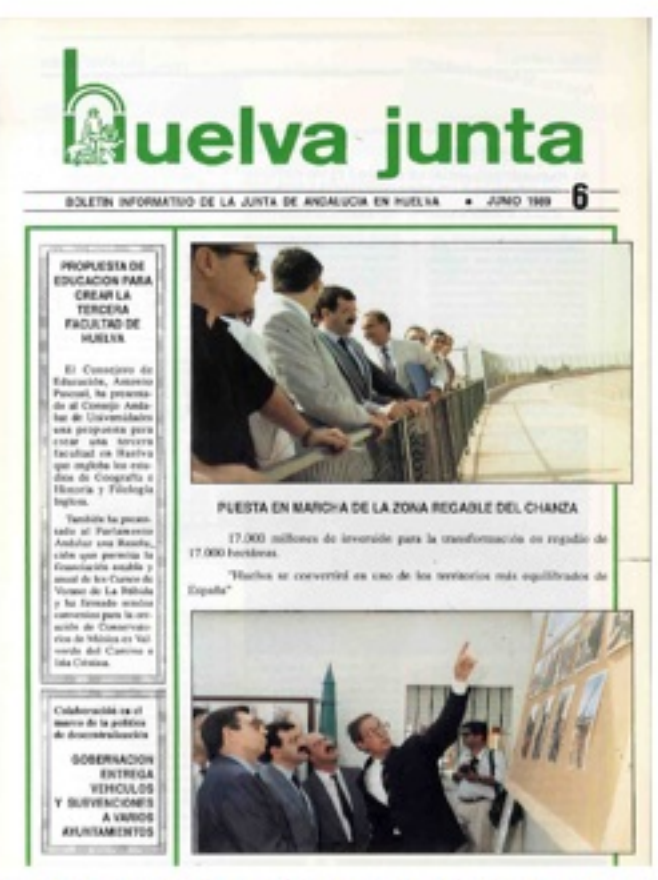

Huelva Junta (1980), editada por la Junta de Andalucla en Huelva.

Fuente: Archivo privado de Gloria Menéndez.

Con estas premisas, el periódico se dedicó a desglosar los proyectos llevados a cabo por la administración autonómica en Huelva, resaltando la visita que realizaron a la provincia sus máximos representantes, como sucedió a mediados de 1989 con el entonces presidente de la Junta de Andalucía José Rodríguez de la Borbolla, que acudió a conocer las obras de la zona regable del Chanza. Por cierto, que la revista apareció en 1989, último año de Rodríguez de la Borbolla en la presidencia de la Junta de Andalucía. Su sustitución en 1990 por Manuel Chaves parece afectar a Huelva Junta, puesto que desapareció con el cambio de legislatura.

El periódico se realizaba a todo color, con el predominio del verde de la bandera andaluza, que aparecía en la cabecera y en un recuadro que enmarcaba cada página. Su maquetación era ligera, equilibrada y atractiva, con un predominio de las fotografías. El formato de Huelva Junta fue de $21 \times 31$ centímetros.

\section{CONCLUSIONES}

La prensa institucional en España -como se ha demostrado en este análisis de las publicaciones periódicas onubenses- inició su desarrollo y expansión a inicios de la democracia, etapa en la que este tipo de información se iba a convertir en habitual en la sociedad. Tanto es así que hoy en día es una de las piezas clave de cualquier medio de comunicación. A veces hasta copa la mayor parte de las noticias difundidas.

Y es que la restricción de las libertades influyó en la prensa española desde los años cuarenta a los sesenta. Por este motivo, el final de la dictadura significó la proliferación de nuevas publicaciones, un espíritu que pronto fue adquirido por las administraciones públicas que se fueron configurando al abrigo del sistema democrático.

En este aspecto, la provincia onubense fue un claro exponente de esa revitalización mediática a nivel institucional, por ejemplo, con la difusión de los boletines municipales del Ayuntamiento de Huelva, primero, y las revistas informativas de la Diputación Provincial y la Junta de Andalucía, después. Para comprobarlo tan sólo hay que observar la tabla en la que recopilamos las publicaciones institucionales surgidas en Huelva y analizadas en el presente estudio (Tabla 1). 


\begin{tabular}{|c|c|c|c|}
\hline TITULO & FECHA & CARACTER & ERIODICIDAD \\
\hline $\begin{array}{l}\text { Boletín Informativo } \\
\text { Municipal de Huelva }\end{array}$ & 1976 & $\begin{array}{c}\text { Revista oficial del } \\
\text { Ayuntamiento de } \\
\text { Huelva }\end{array}$ & Trimestral \\
\hline Huelva & $1980-1984$ & $\begin{array}{c}\text { Revista oficial } \\
\text { Diputación Provincial } \\
\text { de Huelva }\end{array}$ & Trimensual \\
\hline Lluvia & 1982 & $\begin{array}{c}\text { Magazine } \\
\text { Ayuntamiento de } \\
\text { Huelva }\end{array}$ & \\
\hline Huelva Municipal & 1983-1995 & $\begin{array}{c}\text { Revista oficial del } \\
\text { Ayuntamiento de } \\
\text { Huelva }\end{array}$ & \\
\hline Huelva 79 & 1986 & $\begin{array}{c}\text { Revista oficial } \\
\text { Diputación Provincial } \\
\text { de Huelva }\end{array}$ & Trimestral \\
\hline Huelva Junta & 1989 & $\begin{array}{c}\text { Revista oficial Junta } \\
\text { de Andalucia en } \\
\text { Huelva }\end{array}$ & Mensual \\
\hline $\begin{array}{c}\text { El nexo que hace } \\
\text { falta }\end{array}$ & 1999 & $\begin{array}{c}\text { Revista oficial } \\
\text { Trabajadores de la } \\
\text { Diputación Provincial } \\
\text { de Huelva }\end{array}$ & Semestral \\
\hline Ipunto & 2006 & Juvenil Municipal & Gratuito \\
\hline
\end{tabular}

Fuente: Elaboración propia.

Con los años, la información institucional se ha convertido en algo tan profusa que puede llegar a generar infoxicación dada la "sobreabundancia de información generada por el incremento exponencial de la misma", provocando con ello "inevitablemente, una saturación o intoxicación informacional que provoca que muchos sujetos tengan una visión confusa, ininteligible y de densa opacidad sobre la realidad que les rodea" (Area: 2012, 14-15). Es decir, en muchas ocasiones este exceso de noticias de carácter institucional tan sólo está provocando un rechazo o una desatención a este tipo de cuestiones por parte de la sociedad.

Es tan sólo una consecuencia del giro que da el periodismo en la Transición Democrática, un periodo que en materia de prensa se caracterizó por la aparición de multitud de nuevas publicaciones, no sólo en el ámbito institucional. Entonces, todas las asociaciones, colectivos sociales y demás entidades del país quisieron editar su propia revista en la que exponer sus inquietudes y realizar sus demandas tras décadas en silencio.

Un problema, el de la infoxicación, que se ha ido incrementando desde finales del siglo XX con los medios de carácter digital o, simplemente, con la difusión de noticias a través de las páginas web de los diarios (Castillo: 2011), donde la información institucional suele seguir marcando la portada de los medios digitales, salvo casos muy particulares.

En concreto, fue en 1994 cuando España comienza a sumarse al formato multimedia, "como la mayoría de sus colegas europeos" (Barrera: 2004, 410). No en vano, en 1996 ya había 28 cabeceras españolas disponibles en internet (Fuentes: 1997, 335). Huelva se ha unido a esta tendencia con diarios digitales propios, portales que cada vez cuentan con más adeptos. Este proceso, de hecho, ha abierto un debate sobre las consecuencias que puede tener la presencia de información gratuita en internet a un solo click. Lo que no parece tan claro es si el formato digital acabará con siglos de reinado del papel prensa, aunque todo parece indicar que convivirán los dos formatos, como ya sucedió con la radio y la televisión.

La polarización de las líneas editoriales o el interés político por el control de los pequeños periódicos provinciales marcan gran parte de la realidad actual de los medios (Iglesias: 1989, 437), lo que puede ser la causa del incremento de casos de infoxicación, un concepto que continuará dando que hablar en el futuro.

\section{Referencias bibliográficas}

AREA, M. y PESSOA, T.: "De lo sólido a lo líquido: las nuevas alfabetizaciones ante los cambios culturales de la Web 2.0", Comunicar, nº 38 (marzo 2012) pp. 13-20. 
BARRERA, C.: Los medios de comunicación en España. En BARRERA, C. (2004): Historia del Periodismo Universal. Barcelona: Ariel, pp. 285-318.

BRAOJOS GARRIDO, A. (1985): Guía de la Hemeroteca Municipal de Sevilla. Volumen II. Sevilla: Ayuntamiento de Sevilla, delegación de cultura ISBN 8450525454

CAL MARTíNEZ, M. R: Fórmulas nuevas de información local. En TIMOTEO ÁLVAREZ, J. (1989): Historia de los medios de comunicación en España. Periodismo, imagen y publicidad (1900-1990). Barcelona: Ariel, pp. 488-498.

CASTILLO, J. M. (2011): Teleperiodismo en la era digital. Madrid: Instituto Oficial de Radio y Televisión ISBN 978-84-88788-83-2

CHECA GODOY, A. (1991): Historia de la prensa andaluza. Sevilla: Fundación Blas Infante ISBN 84-86814-57$\mathrm{X}$ (2011): Historia de la prensa andaluza. Sevilla:Alfar ISBN 978-84-78984-07-7

CORNELLA, A.: “Cómo darse de baja y evitar la infoxicación en internet'. Extra!-Net, vol. 187 (diciembre 1996), pp. 1-2.

ESCOBAR ROCA, G. (2002): Estatuto de los periodistas. Régimen normativo de la profesión y organización de las empresas de comunicación. Madrid: Tecnos ISBN 843093765X

FARIAS BATLLE, P.: "El papel de la prensa en la transición española. La prensa y las transiciones políticas a la democracia", Comunicar, vol. 13 (1999), pp. 71-77.

FERIA VÁZQUEZ, P. (2009): Los protagonistas del cambio político. Transición a la democracia en la ciudad de Huelva (1964-1980). Huelva: Diputación de Huelva ISBN 978-84-81634-58-7

FUENTES, J. F. y FERNÁNDEZ SEBASTIÁN, J. (1997): Historia del Periodismo Español: prensa, política y opinión pública en la España contemporánea. Madrid: Síntesis ISBN 84-7738-497-5

GRIJELMO, A.:La democracia en los ayuntamientos. En VV. AA. (1996): Memoria de la Transición. Madrid: Taurus, pp. 371-378

IGLESIAS, F.: Las transformaciones de la prensa diaria. En TIMOTEO ÁLVAREZ, J. (1989): Historia de los medios de comunicación en España. Periodismo, imagen y publicidad (1900 - 1990). Barcelona: Ariel, pp. 436444.

NICOLÁS MARÍN, E.: La Transición se hizo en los pueblos. La vida política en Murcia (1968-1977). En QuirosaCheyrouze, P. y Muñoz, R. (2007): Historia de la Transición en España. Los inicios del proceso democratizador. Madrid: Biblioteca Nueva, pp. 251-267.

MUÑOZ SORO, J.: Parlamentos de papel: la prensa crítica en la crisis del franquismo. En QUIROSACHEYROUZE P. y MUÑOZ, R. (2007): Historia de la Transición en España. Los inicios del proceso democratizador. Madrid: Biblioteca Nueva, pp. 449-461.

NAVAS-MARTÍN, M. Á. et al: "Acceso a fuentes de información sobre salud en España: cómo combatir la infoxicación”. Enfermería Clínica, vol. 22 (3), (2012), pp.154-158.

RAUSELL KÖSTER, C. y RAUSELL KÖSTER, P. (2002): Democracia, información y mercado. Propuestas para democratizar el control de la realidad. Madrid: Tecnos ISBN 8430938036

RUIZ ROMERO, M.: "La prensa andaluza durante la Transición”. En Ámbitos. Revista Andaluza de Comunicación, vol. 1, (1998), pp. 231-252.

: "La constitución de la Junta de Andalucía en la génesis del "Estado de las autonomías", Hispania 
Nova, Revista de Historia Contemporánea, vol. 2 (2001), pp. 6.

VV. AA. (2007): Elecciones municipales mayo 2007. Madrid: Ministerio del Interior.

\section{Referencias Hemerográficas}

- El Nexo que hace falta (1999). Archivo propio.

- Huelva (1980). Archivo privado de Rafael Terán.

- Huelva Junta (1980). Archivo privado de Gloria Menéndez.

-Huelva Municipal (1983 - 1995). Archivo privado de José Luis Jerez Manfredi.

- Ipunto (2006). Ayuntamiento de Huelva.

\section{Semblanza biográfica de la autora}

Mari Paz Díaz Domínguez es periodista y doctora en Historia del Periodismo por la Universidad de Huelva. Licenciada en Periodismo por la Universidad de Sevilla y en Historia por la Onubense. Es miembro del Grupo de Investigación Ágora.

Ámbitos. Revista Internacional de Comunicación, n.26, año 2014, tercer trimestre (otoño). 